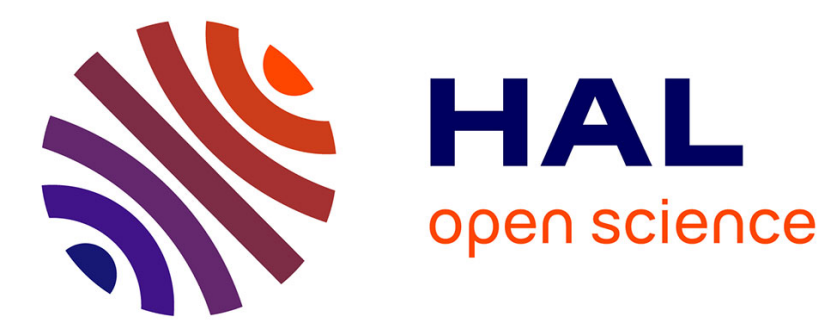

\title{
Wood chips flow in a rotary kiln: experiments and modeling
}

Baptiste Colin, Jean-Louis Dirion, Patricia Arlabosse, Sylvain Salvador

\section{To cite this version:}

Baptiste Colin, Jean-Louis Dirion, Patricia Arlabosse, Sylvain Salvador. Wood chips flow in a rotary kiln: experiments and modeling. Chemical Engineering Research and Design, 2015, 98, pp.179-187. 10.1016/j.cherd.2015.04.017 . hal-01165159

\section{HAL Id: hal-01165159 https://imt-mines-albi.hal.science/hal-01165159}

Submitted on 18 Jun 2015

HAL is a multi-disciplinary open access archive for the deposit and dissemination of scientific research documents, whether they are published or not. The documents may come from teaching and research institutions in France or abroad, or from public or private research centers.
L'archive ouverte pluridisciplinaire $\mathbf{H A L}$, est destinée au dépôt et à la diffusion de documents scientifiques de niveau recherche, publiés ou non, émanant des établissements d'enseignement et de recherche français ou étrangers, des laboratoires publics ou privés. 


\section{Wood chips flow in a rotary kiln: experiments and modeling}

Colin, B., Dirion, J-L.*, Arlabosse, P., Salvador, S.

Université de Toulouse, Mines Albi, CNRS UMR 5302, Centre RAPSODEE, Campus Jarlard, F-81013 ALBI Cedex 09, FRANCE.

${ }^{*}$ Corresponding author:

dirion@enstimac.fr

\section{Abstract}

Rotary kilns are well suited for processing woody biomass by torrefaction to produce bioenergy. One of the key issues for process design lies in the flow pattern modeling. The Saeman model is classically used to predict the mean residence time (MRT) and the bed depth profile of powder materials in rotary kilns. Its ability to describe wood chips flow arises. In the present study, residence time distribution (RTD) experiments are conducted with raw and torrefied wood chips. Effects of operating parameters kiln slope, rotational speed and inlet flow-rate - on the average residence time, the variance and the mean solid hold-up are discussed. A plug flow with small extent of dispersion is emphasized, even if some segregation phenomena are highlighted. Torrefaction did not evidence any significant influence on the flow pattern. With a discrepancy of $20 \%$ between the measured and computed mean residence time, the predictive capacity of the classical Seaman model proved to be insufficient. The model is adapted to predict accurately the load profile and the mean residence time of particles with parallelepiped form. The discrepancy between experimental and calculated results is so reduced from 20 to $5 \%$ for the MRT and from 25 to $5 \%$ for the mean solid hold-up.

Keywords: rotary kiln; wood chips; torrefaction; residence time distribution; axial dispersion

\section{Introduction}

Torrefaction of biomass is a thermal treatment under inert atmosphere at low temperature $\left(250-300{ }^{\circ} \mathrm{C}\right)$. Due to the degradation of hemicelluloses - one of the biomass components - the torrefied products have new properties (Van der Stelt et 
al. 2011). For instance, they are more hydrophobic (Acharjee et al. 2011), more brittle (Bergman et al. 2004) and have a larger energy density than the raw biomass (Phanphanich \& Mani 2011). Several technologies have been identified to perform torrefaction (Sun et al. 2011), the most common being the fluidized beds (AtienzaMartínez et al. 2013), the fixed beds (Ratte et al. 2011), the multiple hearth furnaces (Batidzirai et al. 2013) and the rotary kilns (Mei et al. 2015). Among these reactors, the rotary kiln presents the advantage of being widespread in the industry for processing various materials, like minerals, coke, cement and various wastes ( $\mathrm{Li}$ et al. 2002), in a wide range of temperatures. Indeed, rotary kilns are used at low temperature - below $200^{\circ} \mathrm{C}$ - for drying (Shene \& Bravo 1998), but also at high temperature - above $500^{\circ} \mathrm{C}$ - for calcination (Mujumdar \& Ranade 2006). Consequently, the rotary kilns look promising reactors to perform torrefaction.

The torrefaction yield is mainly governed by the temperature level and by the reaction's duration (Medic et al. 2012). In a rotary kiln, the movement of particles depends on the operating parameters. A majority of kilns operates in the rolling mode, which allows a good mixing of the bed (Boateng \& Barr, 1996 ; Ding et al., 2002). The bed can be divided into two distinct parts: an active layer and a passive layer also called plug flow region. The active layer is the smaller one and is located at the free surface of the bed. It is formed by particles that roll from the top to the bottom of the inclined surface. There, at the end of the rolling movement, particles enter the plug flow region that follows the movement of the wall of the kiln and brings particles at the free surface. As a consequence, the axial movement of particles occurs mainly when rolling in the active layer, due to gravity forces. These observations are the key to understand phenomena, such as segregation, but also to model heat and mass transfer. In addition to the temperature level, the mean residence time, the dispersion of the residence time distribution but also the solid hold-up have an influence on the thermal history of each particle in the rotary kiln. Therefore, characterizing the flow pattern and the solid hold-up are one of the main challenges for performing wood chips torrefaction in a rotary kiln.

Residence time distributions in rotary kilns have already been extensively characterized for granular packing of spherical and regular particles such as sand, powder, grains and so on (Sai et al. 1990). The model first established by Saeman (1951) provides the bed depth profile along the kiln and the solid hold-up, in addition 
to the mean residence time. This is of particular interest for modelling the whole process because it gives details about the transfer surfaces between the wall, the gas and the solid phases. This work has been further extended to several kiln configurations (Afacan \& Masliyah 1990), but always using sand as feeding material. Currently, the validity of this correlation for irregular particles shapes like wood chips has not been demonstrated. Indeed, these particles have a length-to-thickness ratio higher than 5 and the blend presents a very broad size distribution of particles.

In this study, residence time distributions (RTD) of both raw and torrefied wood chips in a rolling pilot-scale rotary kiln are measured and a method to evidence segregation phenomena is proposed. The influence of the rotational speed, the inclination and the solid inlet flow rate on the RTD curves of the raw biomass is discussed. Secondly, in order to investigate the influence of torrefaction on the flowing behavior of wood chips, results obtained with raw wood are compared with RTD experiments carried out with torrefied wood. Finally, a modified Saeman model describing accurately the bed depth profile along the kiln and the mean residence time of particles is developed and validated by comparison with experimental data.

\section{Materials and methods}

\subsection{Apparatus and materials}

A schematic representation of the pilot rotary kiln used in this study is proposed in Figure 1. It consists of a cylinder of $4.2 \mathrm{~m}$ in length $(L)$ and $0.21 \mathrm{~m}$ in internal diameter $(D)$. The length-to-diameter ratio reaches 20 , which is classical for drying or cooling processes (Kohav et al. 1995). The inner wall is covered by a metal grid to increase the roughness and establish the rolling mode. The inclination $\alpha$ can vary between 0 and $7^{\circ}$ and the rotational speed $\omega$ between 1 and $21 \mathrm{rpm}$. 


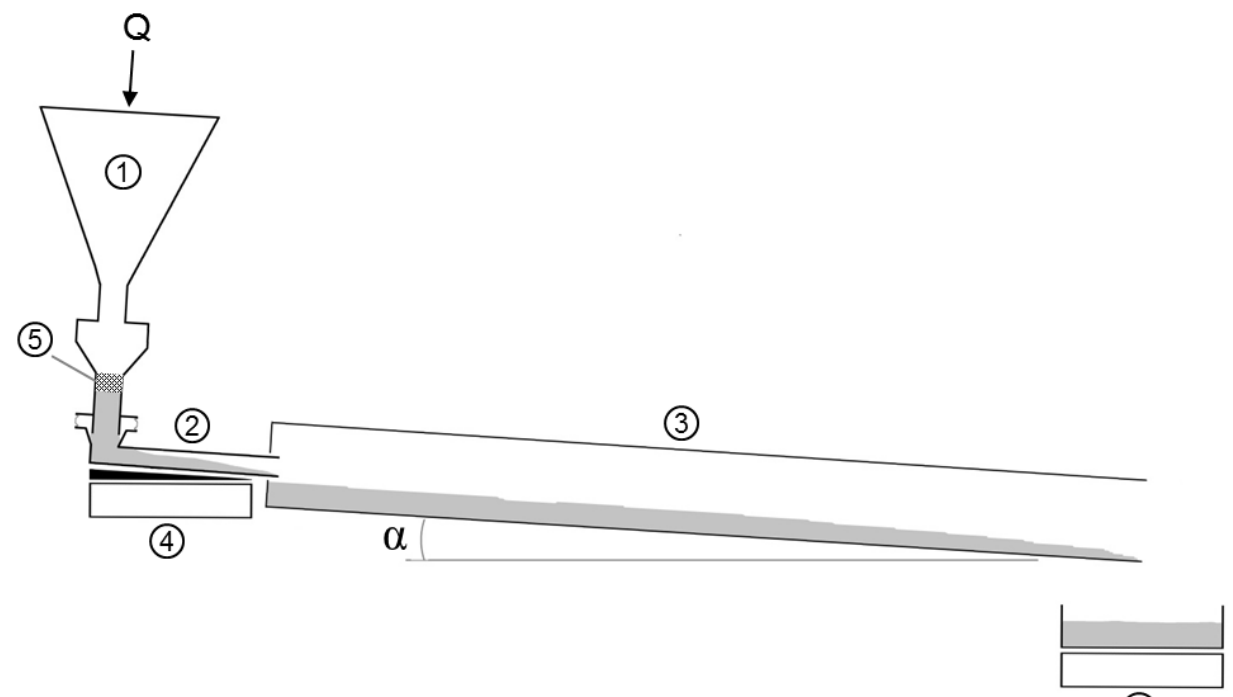

$\omega$

(4)

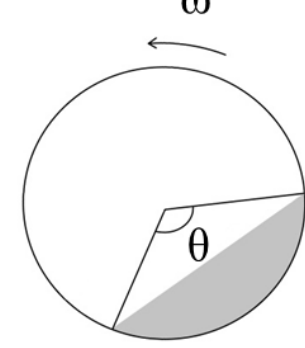

The biomass is introduced at the top end of the hopper and is transported with a vibrating conveyor to the entrance of the rotating cylinder. The hopper has a capacity of $10 \mathrm{~kg}$ of wood chips. The overall feeding system is continuously weighed. The inlet mass flow-rate of wood chips $Q$ - varying from 0 to $10 \mathrm{~kg} / \mathrm{h}$ - is regulated accurately ( $\pm 50 \mathrm{~g} / \mathrm{h}$ ) by controlling the vibration amplitude of the conveyor. When processing in cold conditions - as for the flow study - the kiln end is opened and another weighing system is placed at the end of the cylinder to measure the outlet mass flow-rate. Steady state can thus be identified. On the contrary, for a torrefaction treatment, the kiln is hermetically closed and swept with nitrogen to provide an oxygen-free atmosphere. The cylinder is indirectly heated with an electrical furnace (electrical power $38 \mathrm{~kW}$ ) from room temperature up to the set-point temperature.

Raw and torrefied beech wood chips are used in this study. The raw beech wood chips is provided by the French company SPPS. Characteristics of this material are summarized in Table 1. The torrefied biomass was produced in the pilot rotary kiln. The torrefaction was performed at $270{ }^{\circ} \mathrm{C}$; the wood mass loss was $9.1 \pm 2.7 \%$ on a dry basis (uncertainty is calculated for a $95 \%$ confidence level). As can be seen in Table 1, raw and torrefied particles have similar dimensions. Before the RTD experiments, both materials were stacked in contact with the ambient air, until the thermodynamical equilibrium was reached. Measurements of the dynamic angle of repose inside the rotating cylinder did not evidence any significant influence of the thermal treatment. Considering the measurement uncertainty $\left( \pm 10 \mathrm{~kg} / \mathrm{m}^{3}\right)$, no 
significant difference was observed between the bulk densities of the raw and torrefied biomass. As expected, both materials exhibit significantly different equilibrium moisture contents, the moisture content of the torrefied biomass being smaller than that of the raw chips. Indeed, torrefaction induces the thermal degradation of hemicelluloses, the most hydrophilic polymer of wood (Bergman et al. 2005).

Table 1

\begin{tabular}{ccc}
\hline Biomass type & Raw beech & Torrefied beech \\
\hline Particles length & $5-15 \mathrm{~mm}$ & $5-15 \mathrm{~mm}$ \\
Particles width & $2-7 \mathrm{~mm}$ & $2-7 \mathrm{~mm}$ \\
Particles thickness & $1-3 \mathrm{~mm}$ & $1-3 \mathrm{~mm}$ \\
Moisture content & $12 \%$ & $6 \%$ \\
Dynamic angle of repose $(\beta)$ & $42^{\circ}$ & $42^{\circ}$ \\
Bulk density $(\rho)$ & $280 \mathrm{~kg} / \mathrm{m}^{3}$ & $270 \mathrm{~kg} / \mathrm{m}^{3}$ \\
\hline
\end{tabular}

\subsection{Experimental design}

Operating parameters under investigation in this study are the inlet flow rate, the rotational speed and the slope of the kiln. These parameters are classically regarded as having an impact on the residence time and the solid hold-up in rotary kilns. The gas flow rate is also an important parameter, when the gas is used as heat carrier (Song et al. 2003) or when the air velocity influences solid transportation like in rotary kilns equipped with lifters or processing the solids in a cascading mode (Langrish et al. 2007). Here, the nitrogen velocity is low and the influence of the gas-flow rate is neglected.

Values of parameters range from 1 to $2^{\circ}$ for inclination, from 2 to $4 \mathrm{rpm}$ for rotational speed and from 4 to $8 \mathrm{~kg} / \mathrm{h}$ for the inlet flow rate of wood chips. The pilot could operate in wider ranges of parameters, but it has been chosen to stay as close as possible to the industrial conditions: classically $1-3^{\circ}$ and 1-5 rpm for the inclination and rotational speed, respectively (Boateng, 2008). The objective was initially to implement a full factorial design. Experiments, that would have had to be performed, are represented by the vertices of the cube presented in Figure 2. Two of them are technically impossible to reach, the solid hold-up exceeding the capacity of the kiln. These experiments have been replaced with a run at the center of the cube and another at the center of the upper face of the cube. Even if classical laws established 
for statistically designed experiments are not used hereafter, this scheme is able to provide a maximum amount of information with few experiments. In fact, this layout allows the evaluation of the influence of the three factors - for three levels of each on several variables of interest that will be presented in the next sections.

Figure 2

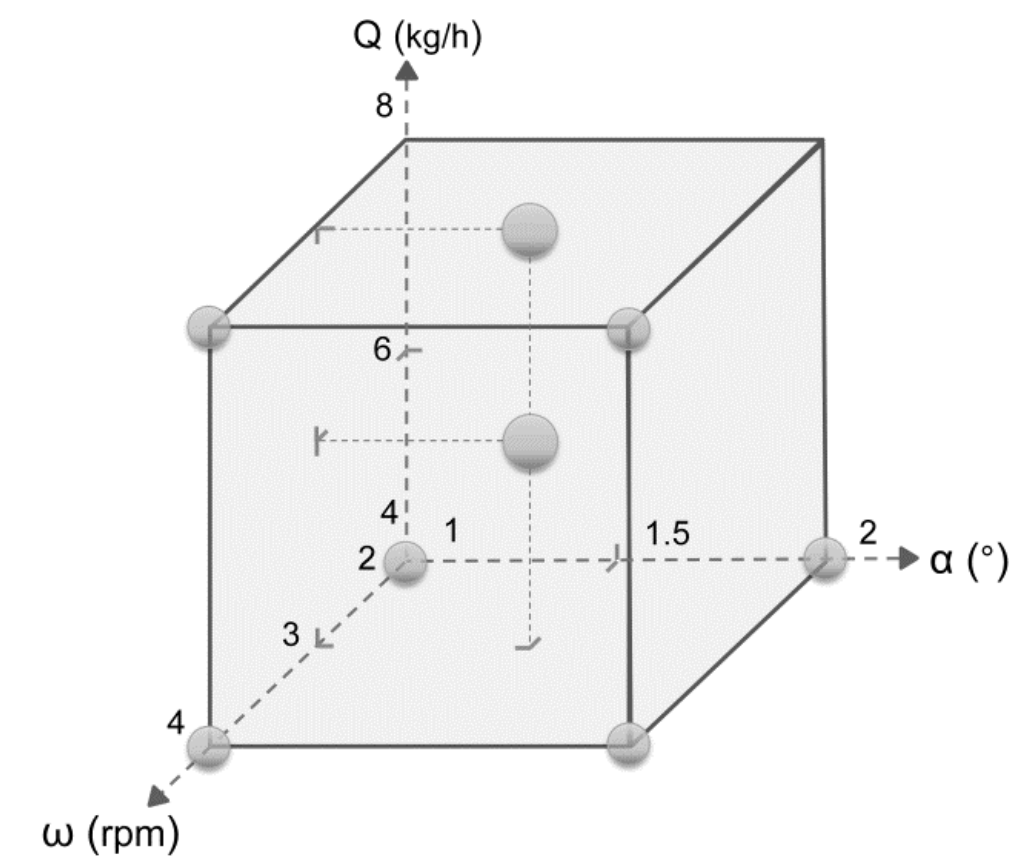

\subsection{Residence time distribution experiments}

The principle of RTD experiments is to analyze the response to a stimulus applied at the entrance of the system. This stimulus can be either a pulse or a step (Levenspiel 1999). In both cases, a tracer is injected at the entrance and is recovered at the exitend of the kiln. Analyzing the evolution of its concentration over time allows the establishment of the RTD curves. To obtain relevant results, the tracer has to be easily recovered and quantified and should not modify the flowing behavior of the material under investigation. In the present study, it has been chosen to use dyed particles. The small amount of ink impregnated inside the chips is supposed not to modify the surface properties of the particles. For this study, a pulse method is applied because it can be performed with a small quantity of tracer.

The experimental protocol is as follows. For each experiment, the parameters of the kiln are adjusted to the desired values and the feeding system is turned on. The steady state is supposed to be reached when the outlet flow rate remains constant, after approximately $3 \mathrm{~h}$. Two tracers (red wood chips and blue wood chips) are then 
injected successively at the bottom end of the hopper at time $t=0$. A preliminary study showed that $40 \mathrm{~g}$ of each tracer are required to obtain accurate results. At the exitend of the kiln, wood chips are sampled every $30 \mathrm{~s}$ during $70 \mathrm{~min}$. Each sample is sorted manually. The two tracers and the uncolored biomass are then weighed separately. For all experiments, the tracer mass recovery is $99.8 \pm 0.4 \%$, which is very high. This allows the calculation of the tracer concentrations $C(t)$ at any time. Knowing the tracer concentration, the exit-age distribution function $E(t)$ is calculated according to Equation 1.

$$
E(t)=\frac{C(t)}{\int_{0}^{\infty} C(t) d t} \quad \text { Equation } 1
$$

The mean residence time $\bar{t}_{s}$ and the variance of the distribution $\sigma^{2}$ are deduced from this function using Equations 2 and 3, respectively.

$$
\begin{gathered}
\bar{t}_{s}=\int_{0}^{\infty} t E(t) d t \quad \text { Equation 2 } \\
\sigma^{2}=\int_{0}^{\infty} t^{2} E(t) d t-\bar{t}_{s}^{2} \quad \text { Equation } 3
\end{gathered}
$$

These two values are characteristic of the residence time distribution for each experiment.

\subsection{Bed depth profile measurement}

When the tracers have been completely recovered, the rotation of the cylinder is stopped. Before emptying the kiln, pictures of the bed of particles are taken. Colored landmarks placed on the internal grid are used for focusing the camera and accurately locating the bed positions along the kiln. For each position, the angle $\theta$, defined in Figure 1, is estimated by processing the pictures with the software Image $\AA^{\circledR}$ (National Institutes of Health, USA). From this angle, the local solid hold-up $h$ is calculated using Equation 4 (Descoins 2003).

$$
h=\frac{\theta-\sin \theta}{2 \pi} \times 100 \quad \text { Equation } 4
$$

Finally, the cylinder is emptied and the mass of wood chips retained in the kiln ( $m_{\text {retained }}$ ) is weighed to calculate the nominal space time $\tau$ and the mean solid hold-up $H$ using Equations 5 and 6.

$$
\tau=\frac{m_{\text {retained }}}{Q} \quad \text { Equation } 5
$$




$$
H=\frac{m_{\text {retained }}}{\rho \times V_{c y l}} \times 100 \quad \text { Equation } 6
$$

Where $Q$ is the inlet mass flow-rate, $\rho$ the bulk density and $V_{c y l}$ the volume of the rotary cylinder.

\section{Experimental results}

\subsection{Residence Time Distributions for raw biomass}

\section{Residence time distribution curves}

For each experimental set of parameters, two residence time distribution curves are obtained: one for the red tracer and the other for the blue tracer. Examples of $E$ curves are given Figure 3. As can be seen, E-curves for red and blue tracers are very similar whatever the operating conditions. This demonstrates the reproducibility of the RTD experiments. The influence of the two main parameters - the rotation speed and the inclination - can also be observed. A decrease of the rotation speed (see Figure 3a) leads to an increase of the residence time of particles in the cylinder. The scatter of the distribution also increases. The same tendency is observed in decreasing the kiln slope as shown in Figure $3 b$. These results are consistent with previous studies (Liu \& Specht, 2006 ; Song et al., 2003).

\section{Figure 3}
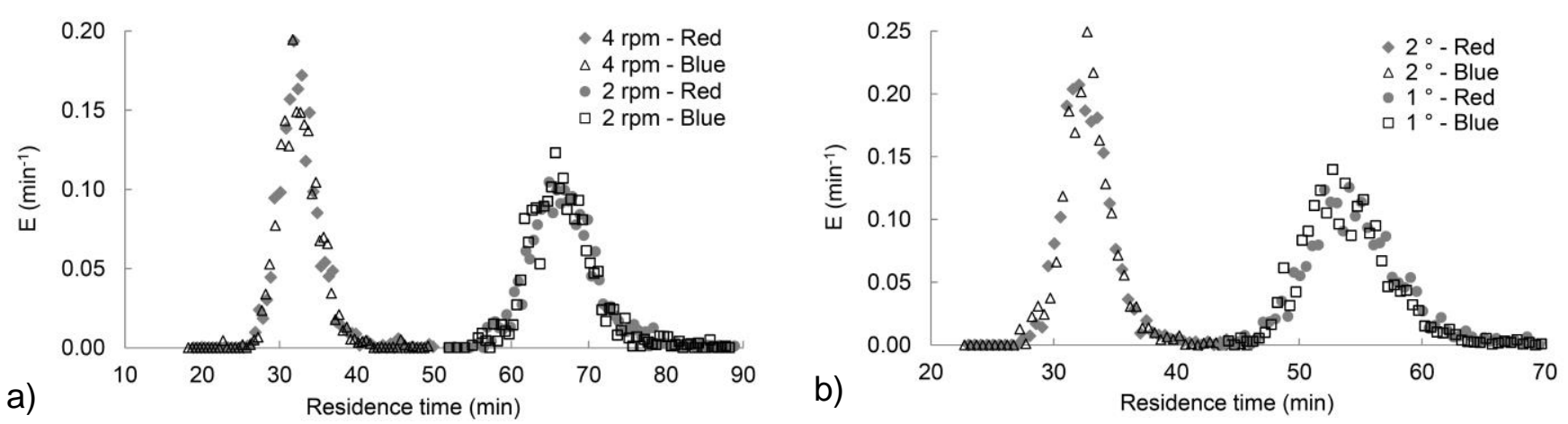

The solid hold-up, the nominal space time, the mean residence time and the standard deviation are summarized in Table 2 for all the experimental runs. Visual observations are confirmed. Increasing the rotational speed or the cylinder inclination induces a decrease of the mean residence time and of the standard deviation. Furthermore, the standard deviation increases linearly with the mean residence time. Comparing runs 2 and 3 highlights that the inlet mass flow rate $Q$ does not significantly affect the residence time distribution. Indeed, the mean residence time and the standard deviation are quite similar for the two runs. However, $Q$ influences 
greatly the mean hold-up. In the absence of an exit dam, the mean hold-up remains low, whatever the working conditions applied. As observed in the literature (Chatterjee et al. 1983), such an end constriction increases the mass of solids retained in the cylinder and provides a uniform bed depth.

Table 2

\begin{tabular}{|c|c|c|c|c|c|c|c|c|c|c|}
\hline \multicolumn{4}{|c|}{ Run parameters } & \multicolumn{4}{|c|}{ Experimental results } & \multicolumn{3}{|c|}{ Modeling results } \\
\hline$N^{\circ}$ & $\begin{array}{c}\alpha \\
\left({ }^{\circ}\right)\end{array}$ & $\begin{array}{c}\omega \\
\text { (rpm) }\end{array}$ & $\begin{array}{c}\mathrm{Q} \\
(\mathrm{kg} / \mathrm{h}) \\
\end{array}$ & $\begin{array}{c}\mathrm{H} \\
(\%) \\
\end{array}$ & $\begin{array}{c}\tau \\
(\min )\end{array}$ & $\begin{array}{c}\bar{t}_{s} \\
(\min )\end{array}$ & $\begin{array}{c}\sigma \\
(\min )\end{array}$ & J & $\mathrm{Pe}$ & $\begin{array}{c}\text { Dax } \\
\left(\times 10^{-5} \mathrm{~m}^{2} / \mathrm{s}\right) \\
\end{array}$ \\
\hline 1 & 1.5 & 3 & 8 & 18.1 & 55.4 & 55.9 & 4.1 & 162 & 525 & 1.0 \\
\hline 2 & 2 & 4 & 8 & 10.6 & 32.3 & 33.0 & 2.6 & 172 & 629 & 1.4 \\
\hline 3 & 2 & 4 & 4 & 5.2 & 31.8 & 32.7 & 2.9 & 171 & 361 & 2.5 \\
\hline 4 & 2 & 2 & 4 & 10.8 & 65.9 & 66.7 & 4.4 & 159 & 583 & 0.8 \\
\hline 5 & 1 & 4 & 4 & 8.8 & 53.6 & 54.6 & 4.2 & 164 & 422 & 1.3 \\
\hline 6 & 1 & 4 & 8 & 16.6 & 50.8 & 54.3 & 3.8 & 163 & 497 & 1.1 \\
\hline 7 & 1 & 2 & 4 & 17.9 & 109.4 & 109.4 & 8.4 & 144 & 411 & 0.7 \\
\hline 8 & 1.5 & 3 & 6 & 13.0 & 52.9 & 54.4 & 4.0 & 163 & 645 & 0.8 \\
\hline
\end{tabular}

Observing the experimental nominal space times brings information about the flowing behavior of wood chips in the rotary kiln. Indeed, a stagnation zone is evidenced when $\overline{\mathrm{t}}_{\mathrm{s}}<\tau$ while observing $\bar{t}_{s}>\tau$ classically highlights a short-circuit (Villermaux 1995). Here, values of $\bar{t}_{s}$ and $\tau$ are very close, emphasizing the absence of defect of the flowing behavior of wood chips in the cylinder. Moreover, the standard deviations for all runs are very low and represent less than $10 \%$ of the mean residence times. The dispersion of particles is thus limited along the cylinder. These observations are of great importance for the homogeneity of the treatment, especially in the case of biomass torrefaction.

\section{Plug flow and tanks-in-series representations}

In order to characterize the flow through a reactor, models describing the residence time distribution curves are implemented. This step is essential to compare results coming from various rotary kilns or from other reactor technologies. Depending on the complexity of flow pattern, models proposed in the literature can be oneparameter or multi-parameters models. In the case of granular transport in rotary kilns, the conventional representations are the model of dispersed plug flow - also called axial dispersion model - and the tanks-in-series model. The main objective of these one-parameter models is to quantify the deviation to ideal cases.

The axial dispersion model, whose parameter is the Peclet number $P e$, quantifies the deviation to the plug flow reactor: the higher the Peclet number, the closer the flow of 
particles approaches plug flow. Equation 7, associated to this model, describes the E-curve.

$$
E_{p}(t)=\frac{1}{2 \bar{t}_{s}} \sqrt{\frac{P e}{\pi}} \exp \left(-\frac{P e\left(\bar{t}_{s}-t\right)^{2}}{4 \bar{t}_{s}^{2}}\right) \quad \text { Equation } 7
$$

This expression is used when considering a flow with small extents of dispersion. The shapes of the E-curves given in Figure 3 are symmetrical, which is representative of small extents of dispersion. This observation justifies the use of Equation 7. To find the Peclet number, it has been proposed to adjust this function to experimental results by minimizing Equation 8 for each run.

$$
f_{p}=\sum_{i=1}^{k}\left(E\left(t_{i}\right)-E_{p}\left(t_{i}\right)\right)^{2} \quad \text { Equation } 8
$$

where $k$ is the number of experimental points.

When the Peclet number is known, the axial dispersion coefficient $D_{a x}$ can be determined using Equation 9.

$$
D_{a x}=\frac{u L}{P e}=\frac{L^{2}}{\bar{t}_{s} \times P e} \quad \text { Equation } 9
$$

where $u$ is the mean axial velocity of particles along the kiln, defined as the ratio of the cylinder length to the mean residence time.

The tanks-in-series model, whose parameter is the number of tanks in series $J$, quantifies the deviation to a perfectly mixed reactor: the more tanks in series there are, the more the behavior of particles is far from a perfect mixer. The E-curve is described by Equation 10 and adjustment is performed by minimizing Equation 11 .

$$
\begin{aligned}
E_{T}(t) & =\left(\frac{J}{\bar{t}_{s}}\right)^{J} \frac{1}{(J-1) !} t^{J-1} \exp \left(-J \frac{t}{\bar{t}_{s}}\right) \quad \text { Equation } 10 \\
f_{T} & =\sum_{i=1}^{k}\left(E\left(t_{i}\right)-E_{T}\left(t_{i}\right)\right)^{2} \quad \text { Equation } 11
\end{aligned}
$$

Results obtained by fitting the experimental curves, for low (Run 3) and high (Run 7) residence times, are plotted in Figure 4. In both cases, experimental data are wellrepresented by models under investigation. For the low residence times, the two curves are nearly superimposed. 

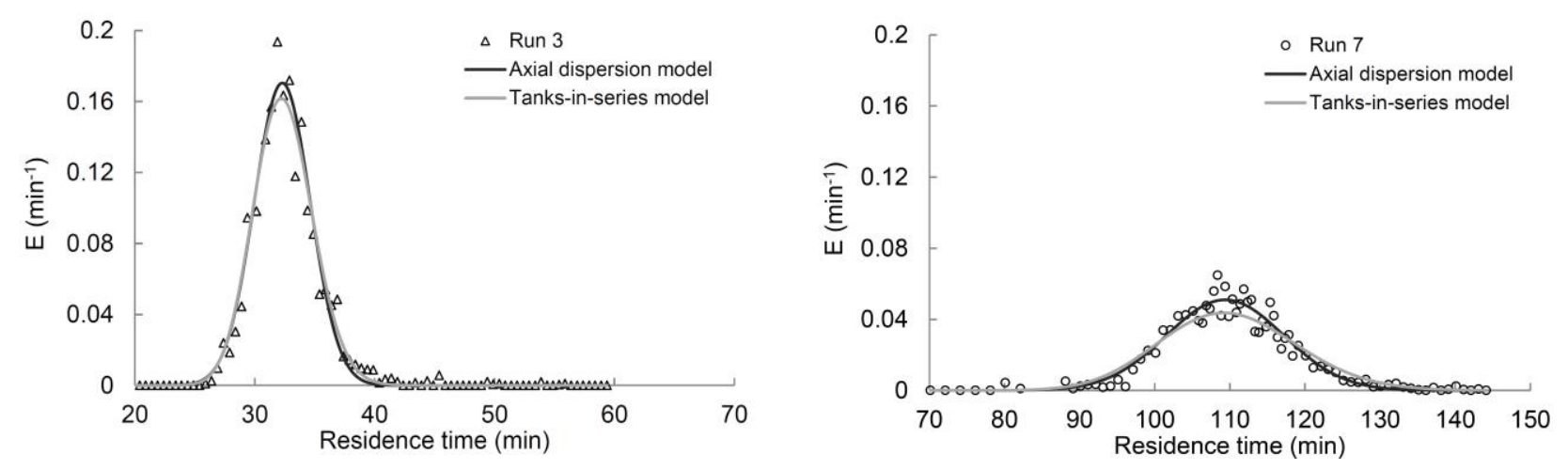

Both models, the axial dispersion and the tanks-in-series models, are thus suitable to represent the residence time distribution of wood chips in the rotary kiln. However, the tanks-in-series model seems to underestimate the amplitude of the E-curves for all runs involving high residence times. Although this discrepancy remains acceptable, the axial dispersion model gives a better agreement with experimental data, whatever the residence times under consideration.

Parameters obtained for these two models after adjustment are reported in Table 2 for all the experiments. As expected (Dinesh \& Sai, 2004 ; Lebas et al., 1995), the Peclet numbers and the numbers of tanks in series are high $(P e>100$ and $J>50)$. This observation highlights that the flow pattern in the rotary kiln presents a small extent of axial dispersion (Levenspiel 1999). Due to the way chosen to estimate theses parameters probably, the equality classically observed $(\mathrm{Pe}=2 \mathrm{~J})$ (Levenspiel 1999) is not verified in this study. Indeed, models have been adjusted on experimental data and not calculated with theoretical correlations. Another explanation can be the scattering of the experimental measurements, particularly near the peak position.

To conclude on the relevance of these results, the estimated data have to be compared to the literature. The Peclet number is not easy to exploit because of its high dependence to the inlet mass flow-rate. Rather, the axial dispersion coefficient has been previously studied in detail (Sherritt et al. 2003) in the case of rotary kilns. Correlations have been established to express it as a function of the rotational speed and the mean solid hold-up. The axial dispersion coefficient increases when the rotational speed increases and decreases when the mean solid hold-up increases. 
These conclusions are consistent with the results of Table 2 and confirm the influence of the inlet mass flow-rate on the Peclet number, via the solid hold-up.

The number of tanks in series presents the advantage of not being affected by the inlet mass flow-rate of biomass. Moreover, it rises proportionally to the mean residence time. The tank's mean length, defined as the ratio of the kiln's length $L$ to the number of tanks $J$, varies between 2.4 and $2.9 \mathrm{~cm}$ for this study. This is in good agreement with the literature (Sai et al., 1990 ; Wes et al., 1976). Usually, the tank's mean length reaches approximately $10 \%$ of the cylinder diameter.

\subsection{Results for torrefied biomass}

To carry out RTD experiments during the torrefaction process, a thermally inert tracer has to be found. Moreover, the torrefaction process is necessarily performed under inert atmosphere, which is not compatible with in-line sampling. Consequently, it has been chosen to compare flowing behaviors of raw and torrefied biomass in cold conditions. Two RTD experiments - runs 9 and 10 - with operating parameters similar to those of run 3 have been performed with torrefied biomass. For these trials, after adjusting the parameters of the kiln to the desired values, the kiln is fed with torrefied biomass. Once the steady state is reached, two successive pulse injections of tracers are performed. For run 9, the tracers are dyed particles of raw biomass and dyed particles of torrefied biomass. For run 10, red and blue dyed particles of raw biomass are introduced. The solid hold-up, the nominal space time, the mean residence time and the standard deviation are reported in Table 3 for these three experiments.

Table 3

\begin{tabular}{|c|c|c|c|c|c|c|}
\hline Run & Material & Tracer & $\mathrm{H}(\%)$ & $\tau(\min )$ & $\bar{t}_{s}(\min )$ & $\sigma(\min )$ \\
\hline 3 & Raw & $\begin{array}{l}\text { Red particles } \\
\text { Blue particles }\end{array}$ & 5.2 & 31.8 & $\begin{array}{l}32.3 \\
32.3\end{array}$ & $\begin{array}{l}2.9 \\
2.9\end{array}$ \\
\hline 9 & Torrefied & $\begin{array}{c}\text { Red particles } \\
\text { Torrefied particles }\end{array}$ & 5.2 & 30.9 & \begin{tabular}{|l}
31.2 \\
31.1 \\
\end{tabular} & $\begin{array}{l}3.6 \\
3.4 \\
\end{array}$ \\
\hline 10 & Torrefied & $\begin{array}{l}\text { Red particles } \\
\text { Blue particles }\end{array}$ & 5.3 & 31.1 & $\begin{array}{l}31.5 \\
31.6\end{array}$ & $\begin{array}{l}3.2 \\
3.2\end{array}$ \\
\hline
\end{tabular}

The E-curves for runs 3 and 9 are plotted in Figure 5. From experiment 9 , it can be conclude that the nature of the tracer does not have any influence on the E-curve. Here again, all the RTD experiments are reproducible. By comparing experiment 3 to runs 9 and 10, it can be concluded that torrefaction does not affect the flow of wood 
chips. Indeed, the mean solid hold up, the nominal space time, the mean residence time and the standard deviation are almost identical. Such a conclusion was expected. Indeed, the geometrical model developed by Saeman (1951) in stationary regime (see below) or more recent works of Spurling et al. (2001) and Descoins et al. (2005) in stationary or dynamic regimes have proven that the characteristics of the axial transport of a granular solid bed in a rotary kiln depend on the dimensions and operating parameters of the kiln (length, diameter, inclination angle, rotational speed, solid flow rate) and two properties of material: the density and the dynamic angle of repose. This latter characterizes the friction between the granular bed and the kiln wall. Since the bulk densities and the dynamic angles of repose are the same for raw and torrefied wood chips (see Table 1), no real difference can be awaited for the same operating conditions in a given kiln.

Figure 5

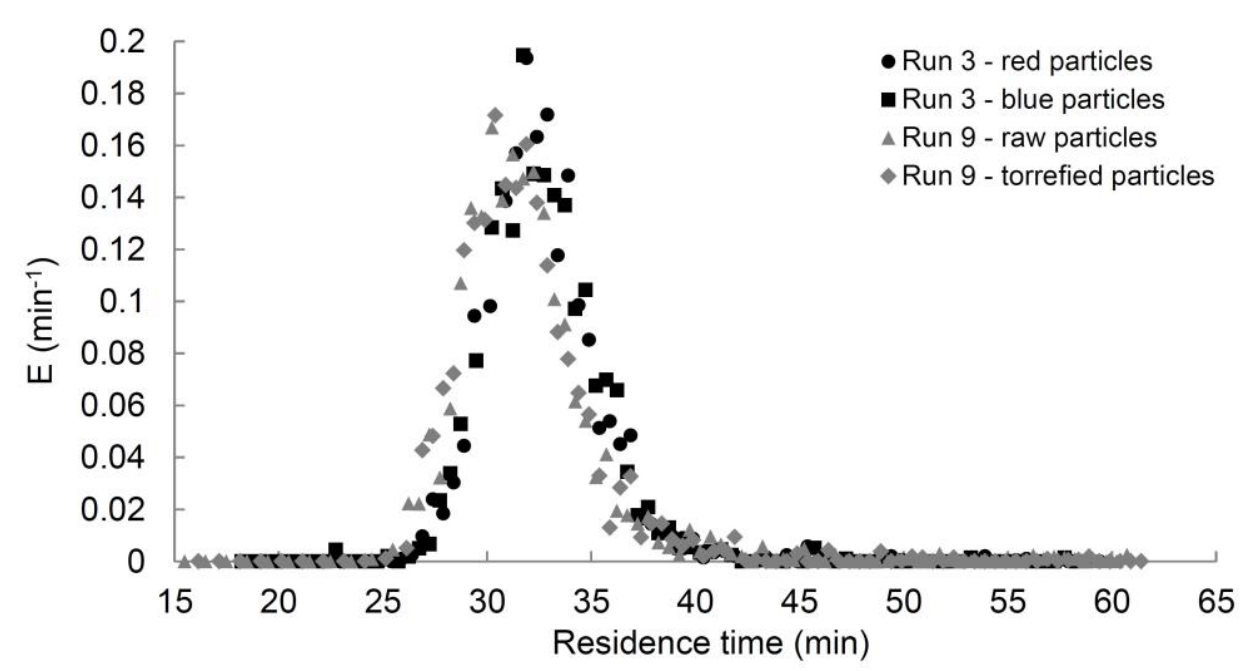

However, it is necessary to keep in mind that these results have been obtained during runs carried out at room temperature. During the torrefaction treatment, other phenomena that occur could modify the behavior of particles. This is especially the case of the volatile matters released during the degradation of wood chips. Nevertheless, at temperatures classically used for torrefaction $\left(250-300^{\circ} \mathrm{C}\right)$, reaction rates are quite low compared to those observed during pyrolysis. Consequently, the main impact of these gases will probably concern the velocity of the atmosphere above the bed, not the behavior of the bed itself. Indeed, the gas yield during torrefaction remains low and it has been observed that only large variations of gas flow-rates have a significant impact on the residence time of particles (Langrish et al. 
2007). Although this aspect has been neglected here, it should be further studied to improve the knowledge on the interactions between the reaction and transport phenomena during a thermal treatment in a rotary kiln.

\subsection{Segregation highlighting}

This experimental work can also bring relevant insights into the influence of particle size on the residence time. At the exit-end of the kiln, wood chips are sampled every $30 \mathrm{~s}$. Sorting the tracers and counting the number of dyed chips in each sample give the average mass of dyed particles in the sample. In Figure 6, this average mass is plotted as a function of time for two specific runs (runs 1 and 3), that are representative of the whole of the experiments. For runs with a high hold-up, the biggest particles reach the kiln end before the small ones. For run 1, a decrease in the average mass of the particles collected at kiln exit is observed for $45<\mathrm{t}<65$ minutes. Due to the small number of dyed particles (typically less than 5) that composes the samples, the measurements are noisy beyond 65 minutes and a representative average mass of particles cannot be computed. On the contrary, no significant trend can be observed for runs with a low hold-up, as for run 3 .

Figure 6
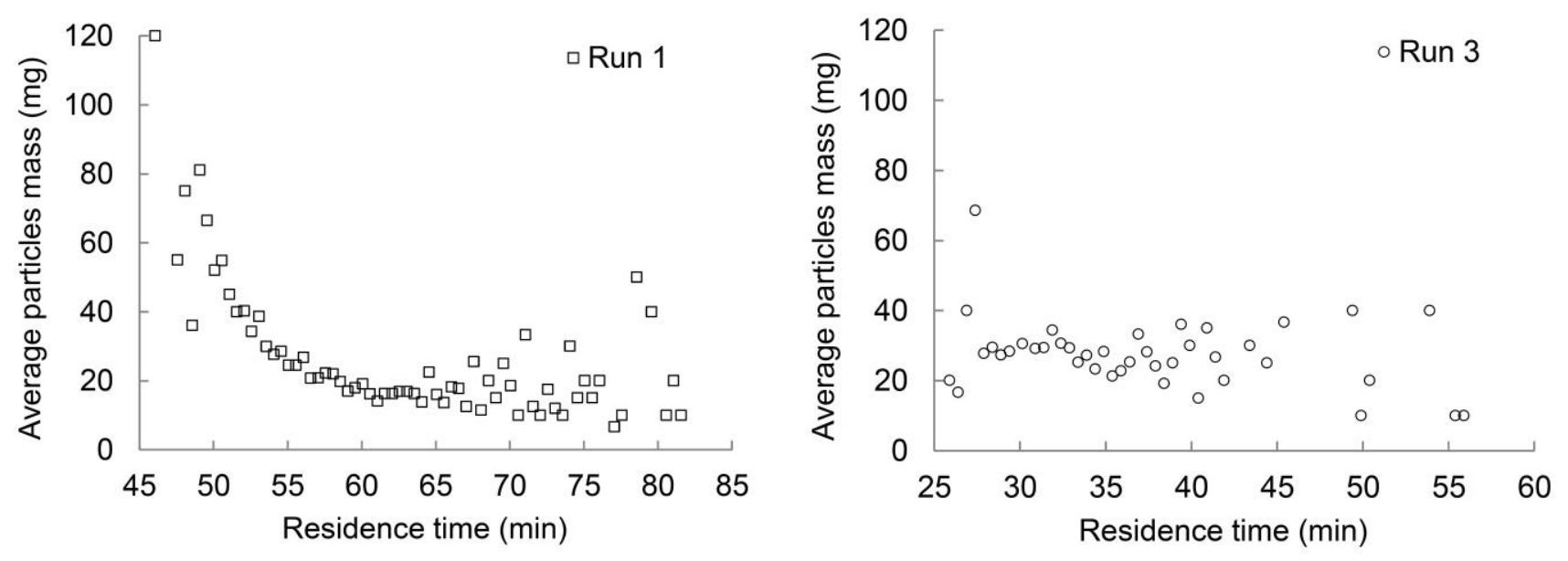

Segregation is thus clearly evidenced in some cases. Such phenomena have already been observed in rotating cylinders (Aït Aissa et al. 2011). The main causes are, of course, differences in particle size and density. But, the moisture content and the surface roughness can also contribute to segregation. At the laboratory scale, most of the studies consider batch horizontal kilns but it has been proven that results 
obtained in a batch reactor are similar to those produced with a continuous process (Ingram et al. 2005). Results of Das Gupta et al., (1991), obtained with a batch setup, are thus suitable for comparison with the present study. Observing sand behavior in a rotating cylinder, axial segregation was assumed to be the consequence of a floating segregation and a radial segregation. The large particles float at the free surface of the bed, and then a core of fine particles appears under the active layer. This core is formed by means of percolation via the voids - among larger particles in the bed. Since the axial movement of particles occurs mainly when rolling in the active layer, the small particles - which stay in the core out of this active layer - flow more slowly. Moreover, it has been observed that the distance that particles can travel in the active layer is proportional to the square of the particle diameter. This is called the trajectory segregation (Boateng \& Barr 1996) and is considered as the main cause of axial segregation.

If all kinds of segregation have been studied in the literature, the experimental studies were often based on binary mixtures, which could be away from industrial realities. The present results from wood chips are thus essential to take into account all phenomena occurring in a torrefaction kiln. Furthermore, one may consider that the segregation is not necessarily a negative phenomenon. Indeed, the biggest particles - staying around the core of fine particles - are closer to the heated wall so will receive more energy than small particles that could react faster. The homogeneity of the torrefaction process could thus be improved. Nevertheless, the difference of residence times for large and fine particles will have to be taken into account when analyzing products of torrefaction.

\section{Bed depth profile and mean residence time modeling 4.1. Model formulation and adjustment}

The Saeman's model (Saeman, 1951) enables the calculation of the bed height as a function of axial position along the rotary kiln, using a non-linear first-order ordinary differential equation with constant coefficients. These coefficients depend both on the operating conditions and the physical properties of the solid. The mass of solid inside the kiln, resulting from the integration of the bed height profile, is divided by the inlet flow rate to obtain the nominal space time, assumed to be equal to the mean 
residence time. This approach is known to work well with model granular packings (Gao et al. 2013) as well as most of the 'conventional' materials such as sand and coal. In Figure 7, the measured mean residence times and hold up are compared with the values predicted with the Saeman's model. Since torrefaction has no influence on the flow pattern, only results obtained with the raw wood chips are used in the following. As can be seen, predictive capacity of the model is not sufficient. Indeed, the predicted mean residence time shows a discrepancy of $20 \%$ with the measured one. This gap rises up to $25 \%$ in the case of the hold-up. Among the parameters appearing in the model, the dynamic angle of repose has the greatest experimental uncertainty. Nevertheless, the profile of the bed is rather not very sensitive to a variation of this parameter and the experimental uncertainty alone cannot explain the differences that prevail.

Figure 7
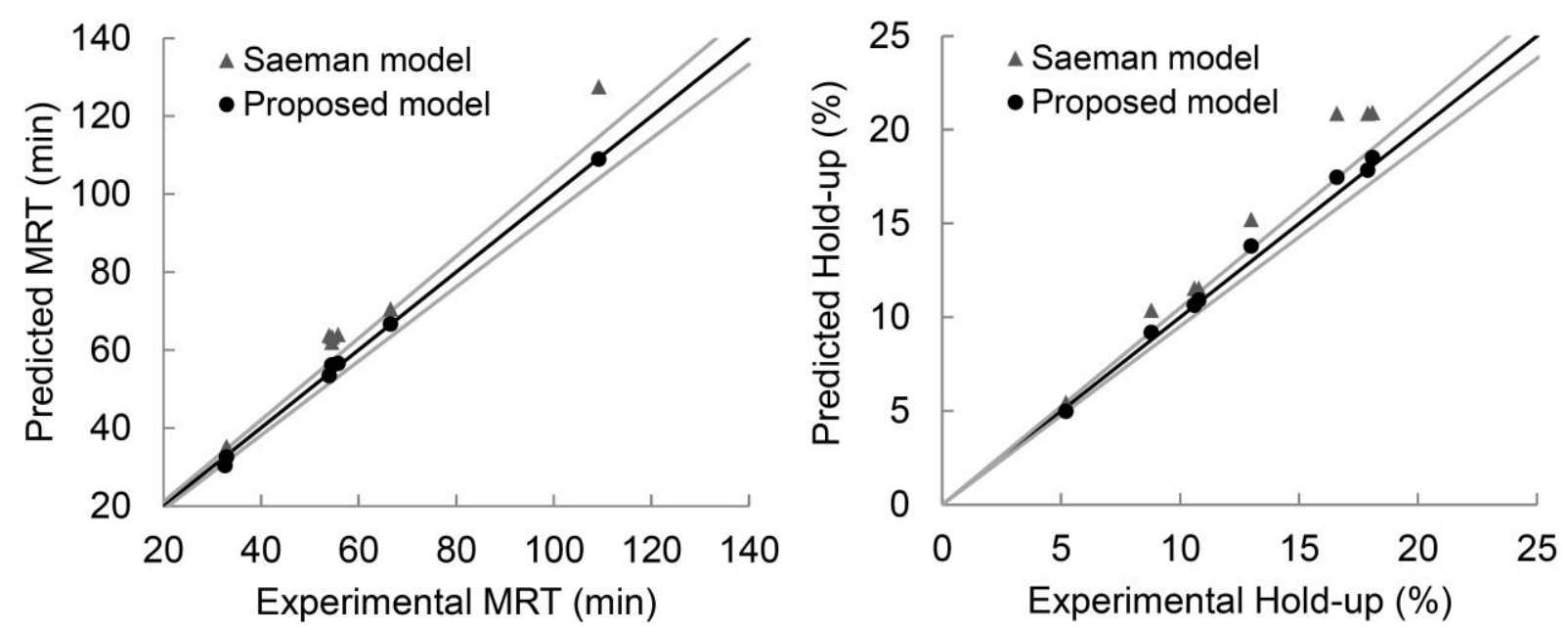

To improve the predictive capacity of the model in the case of wood chips, the original model is modified by adding three coefficients $-C_{Q}, C_{\alpha}$ and $C_{\omega}$ - that adjust the effects of the inlet flow rate, the kiln slope and the rotational speed respectively. The proposed model is described by Equation 12:

$$
\frac{d y(z)}{d z}=\frac{3 Q_{V}^{C} C_{V}^{C} \tan (\beta)}{4 \pi \omega^{C} \omega_{R^{3}}}\left(\frac{2 y}{R}-\frac{y^{2}}{R^{2}}\right)^{-3 / 2}-\frac{\tan ^{c} c_{\alpha}(\alpha)}{\cos (\beta)} \quad \text { Equation } 12
$$

where $y$ is the local bed depth, $z$ the axial position, $R$ the radius of the cylinder and $\dot{Q}_{V}^{E}$ the volumetric inlet flow rate. 
To determine the values of the three coefficients, a nonlinear regression has been implemented to minimize the difference between the measured and the predicted mean residence times.

\subsection{Assessment of the model capacities}

The optimized values for $C_{Q}, C_{\alpha}$ and $C_{\omega}$ are $1.09,1.19$ and 1.11 , respectively. The resulting mean residence time and hold-up are plotted according to the experimental data in Figure 7. With respect to the mean residence time, the deviation to experimental results is lower than $5 \%$. The improvement is especially important for high values. The solid hold-up is predicted accurately too, with a gap smaller than $5 \%$ between calculated and measured values. Another aspect that has to be evaluated is the prediction of the bed depth profile. An example - corresponding to the run 2 - is given Figure 8. The error bars associated to experimental measurements are calculated considering an uncertainty of $\pm 3^{\circ}$ on the determination of the $\theta$ angle. With the proposed model, the discrepency between measured and calculated values are inferior to uncertainties. This was not the case for the model initially proposed by Saeman. The enhancement is particularly highlighted close to the exit of the kiln. In this zone, the Saeman model predicts that the bed depth decreases more suddenly than in reality. Finally, values of coefficients added to correct effects of parameters are very low, which shows that the Saeman's model is very sensitive and needs to be validated before being employed for advanced simulations. As a conclusion, the proposed improvement for the Seaman's model allows a more accurate prediction of the flow pattern of wood chips in a rotary kiln and, in the long term, a better control of torrefaction in a rotary kiln. Indeed, there is a need to calculate the heat transfer surfaces along the kiln to evaluate the contribution of all the heat transfer mechanisms to the charge heating. Knowing accurately the local bed depth profile along the kiln is thus essential. 
Figure 8

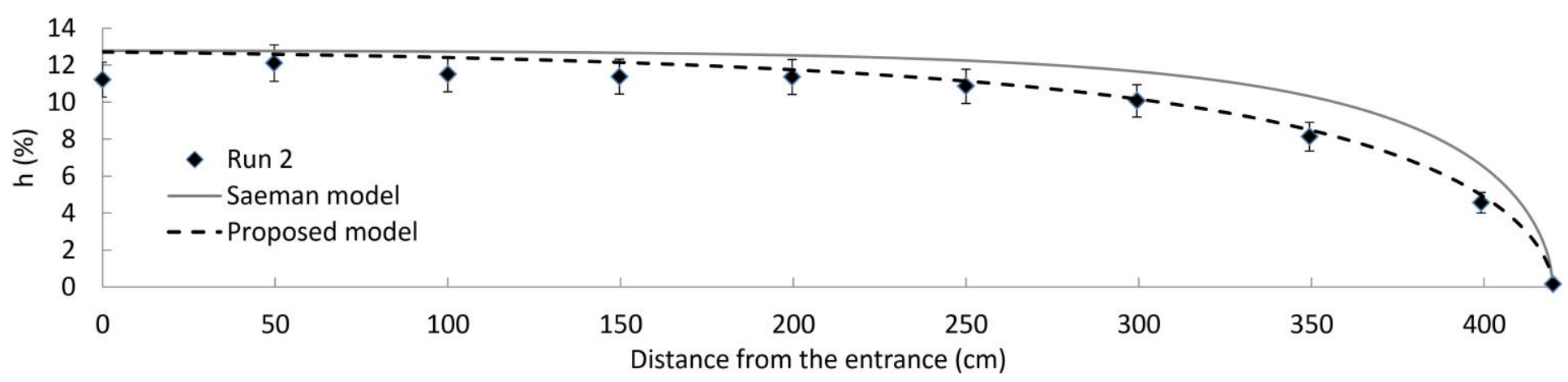

\section{Conclusion}

The present work focused on the control of the residence time of wood chips particles in a rotary kiln, which is an essential parameter to control the torrefaction process. With a few experiments of residence time distribution, many aspects of the wood chips flow in a rotary kiln have been investigated. With classical models adjustment, it has been confirmed that the flow can be considered as a plug flow with a small extent of dispersion. This is crucial for the homogeneity of the thermal treatment. Meanwhile, this homogeneity could be impacted by segregation phenomena that have been highlighted.

Experiments, carried out with raw and torrefied chips, evidenced that the flowing behaviors of these two materials are quite similar at room temperature.

Finally, the effects of operating parameters - kiln slope, rotational speed and inlet flow rate - on the residence time have been quantified and used to improve the Seaman's model for wood chips. This model predicts accurately the load profile in the rotary kiln and the mean residence time of particles. By using the proposed model, the difference between experimental and calculated results is reduced from 20 to $5 \%$ for the mean residence time and from 25 to $5 \%$ for the mean solid hold-up. The load profile, measured by image analysis, is also in good agreement with the prediction of the model.

\section{Acknowledgments}

The authors would like to acknowledge Mickaël Ribeiro and Denis Marty for their technical support. 


\section{Nomenclature}

C Tracer concentration $\left(\mathrm{g} \cdot \mathrm{kg}^{-1}\right)$

$C_{Q} \quad$ Adjustment exponent applied to the volumetric flow rate (-)

$C_{\alpha} \quad$ Adjustment exponent applied to the inclination (-)

$C_{\omega} \quad$ Adjustment exponent applied to the rotational speed (-)

$D \quad$ Internal diameter of the cylinder $(\mathrm{m})$

$D_{a x} \quad$ Axial dispersion coefficient $\left(\mathrm{m}^{2} \cdot \mathrm{s}^{-1}\right)$

E Exit-age distribution function $\left(\mathrm{min}^{-1}\right)$

$E_{p} \quad$ Exit-age distribution function of the axial dispersion model $\left(\mathrm{min}^{-1}\right)$

$E_{T} \quad$ Exit-age distribution function of the tanks-in-series model $\left(\mathrm{min}^{-1}\right)$

$h \quad$ Local solid hold-up (\%)

$H \quad$ Mean solid hold-up (\%)

$J \quad$ Number of tanks in series (-)

$L \quad$ Length of the kiln $(\mathrm{m})$

$m_{\text {retained }} \quad$ Mass of wood chips retained in the cylinder $(\mathrm{kg})$

$\mathrm{Pe} \quad$ Peclet number (-)

$Q \quad$ Mass flow-rate $(\mathrm{kg} / \mathrm{min})$

$\dot{Q}_{V}^{E} \quad$ Volumetric inlet flow-rate $\left(\mathrm{m}^{3} \cdot \mathrm{s}^{-1}\right)$

$R \quad$ Radius of the cylinder $(\mathrm{m})$

$t \quad$ Time (min)

$\bar{t}_{s} \quad$ Mean residence time (min)

$u \quad$ Mean axial velocity of particles along the kiln ( $\left.\mathrm{m} \cdot \mathrm{min}^{-1}\right)$

$V_{c y l} \quad$ Volume of the rotary cylinder $\left(\mathrm{m}^{3}\right)$

$y \quad$ Local bed depth $(\mathrm{m})$

$z \quad$ Axial position in the cylinder $(\mathrm{m})$

\section{Greek letters}

$\begin{array}{ll}\alpha & \text { Inclination of the kiln }\left(^{\circ}\right) \\ \beta & \text { Dynamic angle of repose }\left(^{\circ}\right) \\ \theta & \text { Central angle of sectional solid bed }\left(^{\circ}\right) \\ \rho & \text { Bulk density }\left(\mathrm{kg} \cdot \mathrm{m}^{-3}\right) \\ \sigma^{2} & \text { Variance of the residence time distribution }\left(\mathrm{min}^{2}\right) \\ \tau & \text { Nominal space time }(\mathrm{min}) \\ \omega & \text { Rotational speed }(\mathrm{rpm})\end{array}$




\section{References}

Acharjee TC, Coronella CJ and Vasquez VR (2011) Effect of thermal pretreatment on equilibrium moisture content of lignocellulosic biomass. Bioresource Technology. 102 (7), 4849-54.

Afacan A and Masliyah JH (1990) Solids hold-up in rotary drums. Powder Technology. 61 (2), 179-184.

Aït Aissa A, Duchesne C and Rodrigue D (2011) Longitudinal segregation of polymer powder in a rotating cylinder. Powder Technology. 207 (1-3), 324-334.

Atienza-Martínez M, Fonts I, Ábrego J, Ceamanos J and Gea G (2013) Sewage sludge torrefaction in a fluidized bed reactor. Chemical Engineering Journal 222, 534-545.

Batidzirai B, Mignot APR, Schakel WB, Junginger HM and Faaij APC (2013) Biomass torrefaction technology: Techno-economic status and future prospects. Energy 62, 196214.

Bergman PCA, Boersma AR, Kiel JHA, Prins MJ, Ptasinski KJ and Janssen FJJG (2004) Torrefaction for entrained-flow gasification of biomass. ECN Report, pp. 78.

Bergman PCA, Boersma AR, Zwart RWR and Kiel JHA (2005) Torrefaction for biomass cofiring in existing coal-fired power stations

Boateng AA and Barr PV (1996) Modelling of particle mixing and segregation in the transverse plane of a rotary kiln. Chemical Engineering Science. 51 (17), 4167-4181.

Boateng AA (2008) Rotary kilns: transport phenomena and transport processes. ButterworthHeinemann Ed., pp368.

Chatterjee A, Sathe A and Mukhopadhyay P (1983) Flow of materials in rotary kilns used for sponge iron manufacture: Part II. Effect of kiln geometry. Metallurgical and Materials. 14, 383-392.

Das Gupta S, Khakhar DV and Bhatia SK (1991) Axial segregation of particles in a horizontal rotating cylinder. Chemical Engineering Science. 46 (5/6), 1513-1517.

Descoins N (2003) Contribution à l'élaboration d'outils de simulation des fours tournants dédiés à la pyrolyse de déchets: modélisation dynamique du couplage transport de la charge - transferts de chaleur - réactions chimiques. Thèse de doctorat de l'Institut National Polytechnique de Toulouse.

Descoins N, Dirion J-L and Howes T (2005) Solid transport in a pyrolysis pilot-scale rotary kiln: preliminary results-stationary and dynamic results. Chemical Engineering and Processing. 44 (2), 315-321.

Dinesh V and Sai PST (2004) A Model for Residence Time Distribution of Solids in a Rotary Kiln. The Canadian Journal of Chemical Engineering. 82, 392-398.

Ding YL, Forster R, Seville JPK and Parker DJ (2002) Granular motion in rotating drums: bed turnover time and slumping-rolling transition. Powder Technology. 124 (1-2), 18-27. 
Gao Y, Glasser BJ, lerapetritou MG, Cuitino A, Muzzio FJ, Beeckman JW, Fassbender NA and Borghard WG (2013) Measurement of Residence Time Distribution in a Rotary Calciner. AIChE Journal. 59 (11), 4068-4076.

Ingram A, Seville JPK, Parker DJ, Fan X and Forster RG (2005) Axial and radial dispersion in rolling mode rotating drums. Powder Technology. 158 (1-3), 76-91.

Kohav T, Richardson JT and Luss D (1995) Axial dispersion of solid particles in a continuous rotary kiln. AIChE Journal. 41 (11), 2465-2475.

Langrish TAG, Papadakis SE and Baker CGJ (2007) Residence time of two- and threecomponent mixtures in cascading rotary dryers. Drying Technology. 20 (2), 325-350.

Lebas E, Hanrot F, Ablitzer D and Houzelot JL (1995) Experimental study of residence time, particle movement and bed depth in rotary kilns. The Canadian Journal of Chemical Engineering. 73, 173-180.

Levenspiel O (1999) Chemical Reaction Engineering - Third Edition. John Wiley \& Sons

Li S, Yan J, Li R, Chi Y and Cen K (2002) Axial transport and residence time of MSW in rotary kilns: Part I. Experimental. Powder technology. 126, 217-227.

Liu XY and Specht E (2006) Mean residence time and hold-up of solids in rotary kilns. Chemical Engineering Science. 61 (15), 5176-5181.

Medic D, Darr M, Shah A, Potter B and Zimmerman J (2012) Effects of torrefaction process parameters on biomass feedstock upgrading. Fuel. 91 (1), 147-154.

Mei Y, Liu R, Yang Q, Yang H, Shao J, Draper C, Zhang S and Chen H (2015) Torrefaction of cedarwood in a pilot scale rotary kiln and the influence of industrial flue gas. Bioresource technology. 177, 355-360.

Mujumdar KS and Ranade VV (2006) Simulation of rotary cement kilns using a onedimensional model. Chemical Engineering Research and Design. 84 (A3), 165-177.

Phanphanich M and Mani S (2011) Impact of torrefaction on the grindability and fuel characteristics of forest biomass. Bioresource technology. 102 (2), 1246-53.

Ratte J, Fardet E, Mateos D and Héry J-S (2011) Mathematical modelling of a continuous biomass torrefaction reactor: TORSPYD ${ }^{\mathrm{TM}}$ column. Biomass and Bioenergy $35,3481-$ 3495.

Saeman WC (1951) Passage of solids through rotary kilns. Chemical Engineering Progress. 47 (10), 508-515.

Sai PST, Surender GD, Damoradan AD, Suresh V, Philip ZG and Sankaran K (1990) Residence time distribution and material flow studies in a rotary kiln. Metallurgical and material. 21B, 1005-1011.

Shene C and Bravo S (1998) Mathematical modelling of indirect contact rotary dryers. Drying Technology. 16 (8), 1567-1583. 
Sherritt RG, Chaouki J, Mehrotra AK and Behie LA (2003) Axial dispersion in the threedimensional mixing of particles in a rotating drum reactor. Chemical Engineering Science. 58 (2), 401-415.

Song Y, Thibault J and Kudra T (2003) Dynamic Characteristics of Solids Transportation in Rotary Dryers. Drying Technology. 21 (5), 755-773.

Spurling RJ, Davidson JF and Scott DM (2001) The transient response of granular flows in an inclined rotating cylinder. Chemical Engineering Research and Design. 79 (A), $51-$ 61.

Van der Stelt MJC, Gerhauser H, Kiel JHA and Ptasinski KJ (2011) Biomass upgrading by torrefaction for the production of biofuels: A review. Biomass and Bioenergy. 35 (9), 3748-3762.

Villermaux J (1995) Génie de la réaction chimique - conception et fonctionnement des réacteurs. Ed. Lavoisier Tec \& Doc, 1-448 (in French).

Sun YJ, Jiang JC, Zhao SH, Hu YM and Zheng ZF (2011) Review of Torrefaction Reactor Technology. Advanced Materials Research. 347-353, 1149-1155.

Wes J, Drinkenburg AAH and Stemerding S (1976) Solids mixing and residence time distribution in a horizontal rotary drum reactor. Powder Technology. 13, 177-184. 
Figure 1: Schematic representation of the rotary kiln processing in cold conditions (left) and cross section of the cylinder (right). 1: feeding hopper, 2: vibrating conveyor, 3: rotating cylinder, 4: weighing systems, 5: tracer injection zone.

Figure 2: Spatial representation of the parameters sets used for the experimental study

Figure 3: E-curves for both tracers. Operating conditions: a) $\alpha=2^{\circ} ; \omega=$ variable; $Q=4 \mathrm{~kg} / \mathrm{h} \mathrm{b}$ ) $\alpha=$ variable; $\omega=4 \mathrm{rpm} ; \mathrm{Q}=8 \mathrm{~kg} / \mathrm{h}$

Figure 4: Results of the adjustment procedure of the Axial dispersion and Tanks-in-series models to experimental data for a run at low residence times (Run 3) and a run at high residence times (Run 7)

Figure 5: E-curves obtained during run 3 (raw biomass) and run 9 (torrefied biomass) with different tracers

Figure 6: Evolution of the average particles mass with the residence time for run 1 and run 3

Figure 7: Comparison of the results of the models proposed by Saeman and the one proposed in the present study, with the experimental results. The grey lines define the $\pm 5 \%$ margins

Figure 8: Evaluation of the bed profiles calculated with both models and comparison with experimental measurements 
List of Tables

Table 1: Physical properties of raw and torrefied wood chips

Table 2: Experimental and modeling results of RTD experiments for raw biomass

Table 3: Summary of RTD results for raw and torrefied wood chips 